Article

\title{
Microwave-Assisted Synthesis of Polyols from Rapeseed Oil and Properties of Flexible Polyurethane Foams
}

\author{
Sylwia Dworakowska ${ }^{1, *}$, Dariusz Bogdal ${ }^{1}$ and Aleksander Prociak ${ }^{2}$ \\ 1 Department of Biotechnology and Renewable Materials, Faculty of Chemical Engineering and \\ Technology, Cracow University of Technology, Warszawska 24, Cracow 31-155, Poland; \\ E-Mail: pcbogdal@cyf-kr.edu.pl \\ 2 Department of Chemistry and Technology of Polymers, Faculty of Chemical Engineering and \\ Technology, Cracow University of Technology, Warszawska 24, Cracow 31-155, Poland; \\ E-Mail: aprociak@pk.edu.pl
}

* Author to whom correspondence should be addressed; E-Mail: sylwiadworakowska@gmail.com; Tel.: +48-12-628-2723; Fax: +48-12-628-2947.

Received: 21 May 2012; in revised form: 18 July 2012 / Accepted: 24 July 2012 /

Published: 10 August 2012

\begin{abstract}
The application of raw materials derived from renewable feedstock has given rise to growing interest recently, as it can be exploited for the production of bio-based materials from vegetable oils. Their availability, biodegradability and low prices have been taken into account. In this work, vegetable oil-based polyols as a prospective replacement for petroleum polyols were investigated. A two-stage method for polyol preparation by incomplete epoxidation of natural oils and subsequent complete oxirane ring opening under microwave irradiation is presented. The course of epoxidation and oxirane ring-opening process was determined analytically by an evaluation of iodine, epoxy and hydroxyl values. The samples of oils and their derivatives were also analyzed by FT-IR and characterized by size exclusion chromatography (SEC) in order to calculate their functionalities. Finally, polyols with two different hydroxyl values were obtained and used for the synthesis of flexible polyurethane (PUR) foams. The scope of this research includes the determination of the relationship between the rapeseed oil-based polyol content and the properties of the resulting materials. It was found that applying bio-based polyols in conjunction with petroleum-based polyols for PUR foams formulations resulted in materials with good mechanical properties and a higher number of cells with smaller dimensions.
\end{abstract}


Keywords: renewable feedstock; biopolymer; polyurethane; flexible foam

\section{Introduction}

The depletion of the world crude oil stock, increased prices and more strict regulations relating to the natural environment have increased the demand for renewable resources which is coherent with the sustainable development principles. The application of petrochemical polyols, which play an important role in the polyurethane (PUR) industry, is disadvantageous concerning production, energy and costs. From the viewpoint of environmental protection as well as economics, it is desirable to replace petroleum polyols with vegetable oil-based alternatives in order to manufacture PURs. Some of the most widely applied vegetable oils in the bio-based PURs include the most abundant oils i.e., soybean, palm, rapeseed and sunflower [1-5].

Polyurethanes PURs are important and versatile polymeric materials varying from thermoplastic to thermosetting plastics, which are formed through the polyaddition reaction between organic isocyanates and compounds containing hydroxyl groups, such as polyols. Basically, PUR foams can be classified into two distinct groups, rigid and flexible, depending on their mechanical properties and cross-linking densities [6,7]. Flexible PUR foams are widely used in many diverse applications such as bedding, furniture and in the automotive industry. This is caused by their unparallel performance characteristics, i.e., vibration damping, sound insulation, energy and shock absorption, shape conformance, consumer comfort and protection from impact. These characteristics result from a specific open cell structure of flexible foams, which is built of struts and plateau borders [6-9].

Properties of PUR networks are the result of cross-linking densities related to the number of hydroxyl groups in polyols, their distribution in oils and the position in fatty acids chains. The usage of vegetable oil-based polyols with different functionalities determines the PUR chemical structure [10].

Natural oils consist mainly of triglycerides of saturated and unsaturated fatty acids. They also contain small amounts of mono- and diglycerols, free fatty acids, sterols and tocopherols [11]. The hydroxyl functional derivatives of vegetable oils can be used as green raw materials for the production of PURs for various applications. Rapeseed oil appears to be a good eco-friendly resource for bio-based materials because of its abundance in supply and low cost. Its composition is shown in Table 1. The dominant constituents are (C18) fatty acids. The content of acids in the oil depends on some factors, i.e., type and origin of the oil, its freshness and the refining process [12].

The polyols on the basis of natural oils can be obtained by introduction of hydroxyl groups at the position of double bonds by different ways: hydroformylation or ozonolysis and subsequent hydrogenation, epoxidation followed by oxirane opening, halogen addition and nucleophilic substitution, as well as microbial conversion [4,9]. Vegetable oil-based polyols derived from oil seeds, such as sunflower, soybean, canola and rapeseed, were applied in PUR flexible foams synthesis $[4,9,13,14]$. These modifications had limited success and showed that partial incorporation of vegetable oil-based polyols is much more successful. This article is a continuation of research conducted at Cracow University of Technology in the area of modification of vegetable oils for use in the manufacturing of PUR foams. In the present work, the method of epoxidation of seed oils and 
oxirane ring opening was applied, being the favorable and the most common route for converting oils to polyols for industrial applications. The previous researches related mainly to the synthesis of rigid polyurethane foams, and, in lesser quantities, flexible polyurethane foams with other isocyanate indices than mentioned in this article [15-21]. This report relates to the synthesis of polyols from rapeseed oil using microwave technique and demonstrates the new way of application of rapeseed oil-based polyols as a partial replacement for petrochemical-based polyols in flexible polyurethane foam formulations.

Table 1. Content of fatty acids in rapeseed oil [12].

\begin{tabular}{cllc}
\hline $\begin{array}{c}\text { Number of carbon atoms: } \\
\text { Number of unsaturated bonds }\end{array}$ & \multicolumn{2}{c}{ Fatty acids composition in rapeseed oil } & wt \% \\
\hline $14: 0$ & Myristic & $\mathrm{CH}_{3}\left(\mathrm{CH}_{2}\right)_{12} \mathrm{COOH}$ & 0.1 \\
$16: 0$ & Palmitic & $\mathrm{CH}_{3}\left(\mathrm{CH}_{2}\right)_{14} \mathrm{COOH}$ & 4.5 \\
$16: 1$ & Oleopalmitic & $\mathrm{CH}_{3}\left(\mathrm{CH}_{2}\right)_{5} \mathrm{CH}=\mathrm{CH}\left(\mathrm{CH}_{2}\right)_{7} \mathrm{COOH}$ & 0.4 \\
$18: 0$ & Stearic & $\mathrm{CH}_{3}\left(\mathrm{CH}_{2}\right)_{16} \mathrm{COOH}$ & 2.1 \\
$18: 1$ & Oleic & $\mathrm{CH}_{3}\left(\mathrm{CH}_{2}\right)_{7} \mathrm{CH}=\mathrm{CH}\left(\mathrm{CH}_{2}\right)_{7} \mathrm{COOH}$ & 64.5 \\
$18: 2$ & Linoleic & $\mathrm{CH}_{3}\left(\mathrm{CH}_{2}\right)_{3}\left(\mathrm{CH} \mathrm{CH}_{2} \mathrm{CH}=\mathrm{CH}\right)_{2}\left(\mathrm{CH}_{2}\right)_{7} \mathrm{COOH}$ & 18.3 \\
$18: 3$ & Linolenic & $\mathrm{CH}_{3}\left(\mathrm{CH}_{2} \mathrm{CH}=\mathrm{CH}\right)_{3}\left(\mathrm{CH}_{2}\right)_{7} \mathrm{COOH}$ & 6.8 \\
$20: 0$ & Arachidic & $\mathrm{CH}_{3}\left(\mathrm{CH}_{2}\right)_{18} \mathrm{COOH}$ & 0.8 \\
$20: 1$ & Gadoleic & $\mathrm{CH}_{3}\left(\mathrm{CH}_{2}\right)_{9} \mathrm{CH}=\mathrm{CH}\left(\mathrm{CH}_{2}\right)_{7} \mathrm{COOH}$ & 1.3 \\
$22: 0$ & Behenic & $\mathrm{CH}_{3}\left(\mathrm{CH}_{2}\right)_{20} \mathrm{COOH}$ & 0.4 \\
$22: 1$ & Erucic & $\mathrm{CH}_{3}\left(\mathrm{CH}_{2}\right)_{7} \mathrm{CH}=\mathrm{CH}\left(\mathrm{CH}_{2}\right)_{11} \mathrm{COOH}$ & 0.8 \\
\hline
\end{tabular}

Method for epoxidation of rapeseed oil was carried out with the use of peracetic acid, which was generated in situ and originated from the reaction of hydrogen peroxide and glacial acetic acid in acidic medium. Then the epoxidized oil was converted into the polyol using diethylene glycol (DEG) in the presence of sulfuric acid under microwave irradiation. This is a better way compared to conventional heating as it allows reducing the reaction time and saving energy [20] (Figure 1).

Figure 1. Main reactions of epoxidation and oxirane ring-opening process. R" and R'"-residues of fatty acids.
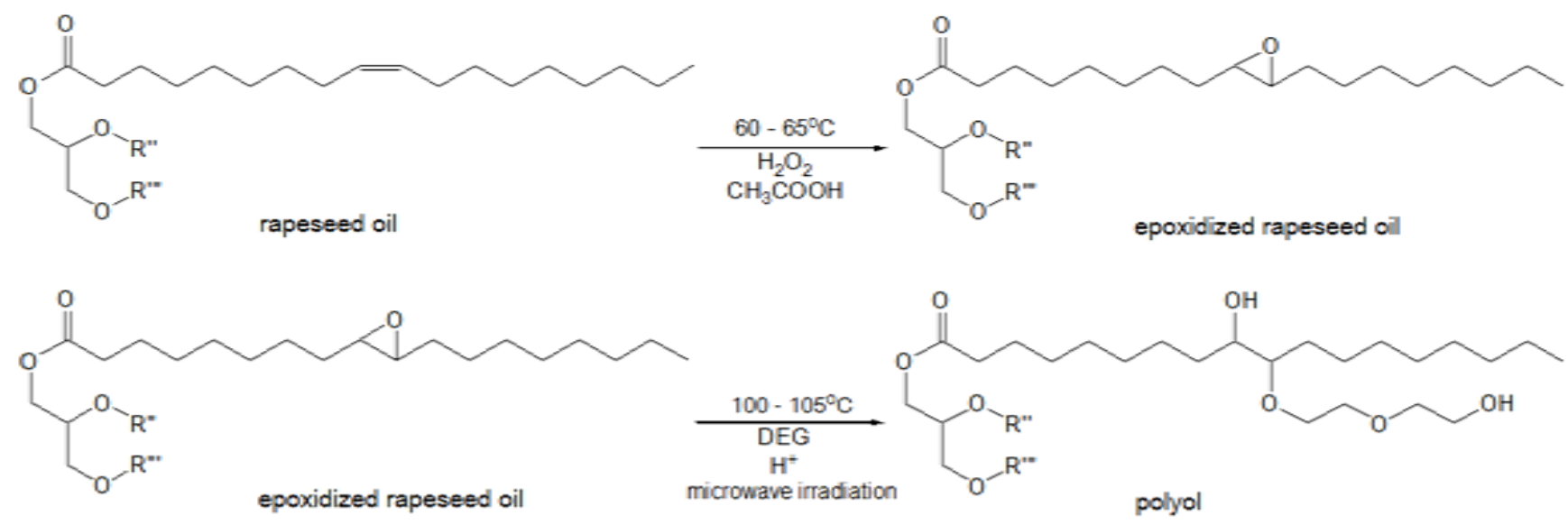

During the epoxidation process, a reversible reaction of carboxylic acid and hydrogen peroxide proceeds with the formation of peracid, which is consumed in the reaction with the unsaturated 
compound. It results in the formation of epoxy and acid reacting again with hydrogen peroxide. The presence of water, mineral and organic acids in the reaction medium is considered to be the main reason for decomposition of the epoxy groups due to hydrolysis or acylation [12]. Ring-opening reactions can be accompanied by oligomerization side reactions, which occur when the newly formed hydroxyl groups react with the existing epoxy groups, thus the selectivity of oil epoxidation rarely exceeds $80 \%$.

The purpose of this paper was to provide an additional insight into the possibility of replacing petroleum polyols with natural oil-based derivatives in PUR formulations. It was found that a partial incorporation of vegetable polyol into flexible foams was successful due to their better properties in comparison to the reference foam.

\section{Experimental Section}

\subsection{Materials}

The food grade rapeseed oil, manufactured by Zakłady Tłuszczowe "Kruszwica" S.A., was used in the studies. The following raw materials obtained from the POCh Gliwice were used in the synthesis of polyols: glacial acetic acid $(99.5 \mathrm{wt} \%)$, toluene $(99.5 \mathrm{wt} \%)$, hydrogen peroxide (30 wt \% aqueous solution), sulfuric acid (95 wt \%), and DEG (diethylene glycol).

The foam formulations were prepared using: Arcol Polyol 1108 (trifunctional polyether polyol, Bayer Material Science LLC), rapeseed oil-based polyols (RDEG 1 and RDEG 2), TDI 80 (toluene diisocyanate 80/20, Zakłady Chemiczne ZACHEM S.A.), Niax Silicone L-627 (Momentive Performance Materials Inc.) and catalysts (Texacat DMCHA (dimethylcyclohexylamine, Texaco Chemical Deutschland GmbH), DABCO BL-11 (70 wt \% bis(dimethylaminoethyl)ether, 30 wt \% dipropylene glycol, Air Products and Chemicals Inc.) and DABCO T-9 (stannous octoate, Air Products and Chemicals Inc.)).

\subsection{Synthesis of Rapeseed Oil-Based Polyols}

The process of preparing polyols was carried out in two steps (Figure 1):

(a) Epoxidation of rapeseed oil

Two rapeseed oils with iodine values $99 \mathrm{~g} \mathrm{I}_{2} / 100 \mathrm{~g}$ and $80.3 \mathrm{~g} \mathrm{I}_{2} / 100 \mathrm{~g}$, respectively, were epoxidized using peracetic acid obtained in situ as a result of the reaction between $30 \mathrm{wt} \%$ hydrogen peroxide and glacial acetic acid. The epoxidation of rapeseed oil was performed in a $4000 \mathrm{~mL}$ round bottom three-neck flask, equipped with a thermometer, stirrer, reflux condenser and dropping funnel. The flask was placed in a heating mantle set for the appropriate temperature. The mixture of rapeseed oil (1200 g), toluene (1200 g), glacial acetic acid and sulfuric acid (18 g) was heated to $55-60{ }^{\circ} \mathrm{C}$. Then hydrogen peroxide was slowly added drop-wise under fast mechanical stirring. The amounts of glacial acetic acid and hydrogen peroxide depended on the expected oxidation degree of the final products. In case of glacial acetic acid $140.4 \mathrm{~g}$ and $113.9 \mathrm{~g}$ were taken, while in the case of hydrogen peroxide $307.7 \mathrm{~g}$ and $175 \mathrm{~g}$ were taken, respectively. Next, the mixture was heated to $65^{\circ} \mathrm{C}$ and stirred for $5.5 \mathrm{~h}$. Then the organic layer was washed with water and two layers were separated. Finally, 
toluene and water residues from the organic layer were distilled off under vacuum to afford the epoxidized rapeseed oils (REPOX 1 and REPOX 2) as light yellow oily liquids.

(b) Microwave-assisted ring-opening reaction

The ring opening of the epoxy groups to hydroxyls was performed [4]. Equimolar amounts of diethylene glycol and sulfuric acid of value equal to $0.3 \mathrm{wt} \%$ of epoxidized oil were added to each oil, REPOX 1 and REPOX 2, respectively. The first mixture consisted of REPOX 1 (500.6 g), DEG (103.6 g) and $\mathrm{H}_{2} \mathrm{SO}_{4}(1.5 \mathrm{~g})$, whereas the second mixture included REPOX 2 (600 g), DEG (78.4 g) and $\mathrm{H}_{2} \mathrm{SO}_{4}(1.8 \mathrm{~g})$. The oxirane ring-opening reaction was carried out under microwave irradiation in a multimode microwave reactor Ertec (Poland) with a frequency of $2.45 \mathrm{GHz}$ and maximum microwave power of $600 \mathrm{~W}$. This process was performed at a temperature of $100-105{ }^{\circ} \mathrm{C}$ for $1 \mathrm{~h}$ by using different powers of the microwave reactor (200-300 W) in order to keep the reaction temperature around $105{ }^{\circ} \mathrm{C}$. Applying the microwave irradiation allowed to reduce the reaction time average of $75 \%$ compared to the process under conventional conditions [20]. As a result, two yellow rapeseed oil-based polyols were obtained, RDEG 1 and RDEG 2, with hydroxyl values equal to $196 \mathrm{mg} \mathrm{KOH} / \mathrm{g}$ and $114 \mathrm{mg} \mathrm{KOH} / \mathrm{g}$, respectively.

\subsection{Characterization of Polyols}

\subsubsection{Analytical Methods}

Iodine, epoxy and hydroxyl values were determined according to the Polish Norms, PN-87/C-04281, PN-87/89085/13 and PN-93/C-89052/03, respectively. The iodine value, as the measure of double bonds content, was determined using the Hanus method. Epoxy oxygen content determination was carried out on the basis of the standard procedure for oils and fats. The hydroxyl values were determined by acetylation procedure.

\subsubsection{FT-IR Analysis}

The FT-IR spectra were recorded on $\mathrm{KBr}$ discs in the wavenumber range of $4000-400 \mathrm{~cm}^{-1}$ on FT-IR BIORAD FTS-165 spectrophotometer.

\subsection{3. ${ }^{1} \mathrm{H}$ NMR Analysis}

${ }^{1} \mathrm{H}$ NMR spectra were recorded using Bruker DRX 300 spectrometer (300 MHz) by applying solvents such as DMF (for rapeseed oil) and $\mathrm{CDCl}_{3}$ (in the case of epoxidized oil and polyol).

\subsubsection{SEC Analysis}

The size exclusion chromatography (SEC) chromatograms were carried out using Knauer GPC chromatograph equipped with two columns of PL-gel $\left(300 \times 7.5 \mathrm{~mm}^{2}\right.$, with a grain size of $3 \mu \mathrm{m}$ and MIXED-E pore), one precolumn and refractometer detector with tetrahydrofuran (stabilized with BHT (2,6-di-tertbutyl-4-methyl phenol)) as eluent. The analysis was performed at a flow rate of $0.8 \mathrm{~mL} / \mathrm{min}$ at a temperature of $30^{\circ} \mathrm{C}$. Polystyrene standards were used for calibration. 


\subsubsection{Rheological Properties}

Rheological properties were analyzed with an Anton Paar Physica MCR 301 rheometer (Anton Paar GmbH, Germany) with plate/cone measurement set-up.

\subsection{Foam Formulation and Preparation}

The flexible foams were prepared by using well-established formulations (Table 2) based upon parts per hundredth parts of the polyol.

Table 2. Foam formulations.

\begin{tabular}{lllllll}
\hline \multirow{2}{*}{ Ingredients } & & \multicolumn{5}{c}{ Formulation ID } \\
& RF-85 $^{\mathbf{a}}$ & R1DG3-85 $^{\mathbf{b}}$ & R2DG3-85 $^{\mathbf{c}}$ & R1DG3-65 $^{\mathbf{d}}$ & R1DG5-65 $^{\mathbf{e}}$ & R1DG7-65 $^{\mathbf{f}}$ \\
\hline Arcol 1108 & 100 & 70 & 70 & 70 & 50 & 30 \\
RDEG 1 & - & 30 & - & 30 & 50 & 70 \\
RDEG 2 & - & - & 30 & - & - & - \\
Water & 6.6 & 6.6 & 6.6 & 6.6 & 6.6 & 6.6 \\
L-627 & 2.5 & 2.5 & 2.5 & 2.5 & 2.5 & 2.5 \\
DMCHA & 0.08 & 0.08 & 0.08 & 0.08 & 0.08 & 0.08 \\
BL-11 & 0.14 & 0.14 & 0.14 & 0.14 & 0.14 & 0.14 \\
T-9 & 0.26 & 0.26 & 0.26 & 0.26 & 0.26 & 0.26 \\
TDI & 60.3 & 67.0 & 63.3 & 51.3 & 54.3 & 57.3 \\
Index NCO & 0.85 & 0.85 & 0.85 & 0.65 & 0.65 & 0.65 \\
\hline
\end{tabular}

${ }^{\mathrm{a}} \mathrm{RF}-85$ - reference foam (Index $\mathrm{NCO}=0.85$ )

${ }^{\mathrm{b}}$ R1DG3-85-foam modified with RDEG 1 (30 wt \% replacement, Index NCO $=0.85$ )

${ }^{\mathrm{c}}$ R2DG3-85-foam modified with RDEG 2 (30 wt \% replacement, Index NCO $=0.85$ )

${ }^{\mathrm{d}}$ R1DG3-65-foam modified with RDEG 1 (30 wt \% replacement, Index NCO =0.65)

${ }^{\mathrm{e}} \mathrm{R} 1 \mathrm{DG} 5-65$ - foam modified with RDEG 1 (50 wt \% replacement, Index NCO $=0.65$ )

${ }^{\mathrm{f}} \mathrm{R} 1 \mathrm{DG} 7-65$ - foam modified with RDEG 1 (70 wt \% replacement, Index NCO =0.65)

The reference foam was prepared with an isocyanate index of 0.85 . The molded foams were obtained by replacement of $30 \mathrm{wt} \%$ of petroleum polyols with rapeseed oil-based polyols: RDEG 1 or RDEG 2. Other foams with an isocyanate index of 0.65 were prepared with 30,50 and 70 wt \% replacement, respectively, with oil-based polyols. The components of PUR mixture were mixed with an overhead stirrer. First of all, polyols, water, silicone and catalysts were weighed into a beaker and stirred for $70 \mathrm{~s}$ at $1500 \mathrm{rpm}$. Then the isocyanate was added and the mixture was stirred again for $10 \mathrm{~s}$ at $2500 \mathrm{rpm}$. The whole mixture was poured into a foaming box which was cured in a $80{ }^{\circ} \mathrm{C}$ oven for $15 \mathrm{~min}$. The foam was then conditioned for no less than $72 \mathrm{~h}$ under ambient conditions $\left(25^{\circ} \mathrm{C}\right.$ and $50 \%$ relative humidity). After conditioning, $5 \mathrm{~cm}$ foam cubes were cut out from the foam.

\subsection{Characterization of Polyurethane Foams}

\subsubsection{Cell Morphology}

The cell structure was studied using an optical microscope with $2.5 \times$ magnification. Small pieces of foam were cut off using a razor blade and viewed under the microscope. The obtained microscope 
pictures were introduced to computer memory through a vision channel and the image analysis was performed using the Aphelion Software in order to evaluate cell size distribution of foams with similar densities.

\subsubsection{Apparent Density}

The bulk density of the foams was measured according to the Polish Norm PN-80/C-89035 (ISO 845). Three samples were cut out from each foam to have a dimension of $50 \mathrm{~mm} \times 50 \mathrm{~mm} \times 50 \mathrm{~mm}$ and then were precisely weighed. The apparent density values were determined in a unit of $\mathrm{kg} \mathrm{m}^{-3}$.

\subsubsection{Compression Force Deflection Test (Compressive Strength)}

The compressive strengths were investigated in accordance to the Polish Norm PN-EN ISO 3386-1:2000, namely determination of stress-strain characteristic in compression using a Zwick Testing Machine (model 1445). The specimens of $50 \mathrm{~mm} \times 50 \mathrm{~mm} \times 50 \mathrm{~mm}$ were compressed to $40 \%$ of their thickness at a speed of $100 \mathrm{~mm} \mathrm{~min}^{-1}$. The average values of compressive strength were obtained from three specimens per sample and reported in a unit of kilopascal $(\mathrm{kPa})$.

\subsubsection{Tensile Properties}

The determination of tensile strength and elongation at break of the foams was carried out according to the Polish Norm PN-EN ISO 1798:2009 also using a Zwick Testing Machine (model 1445). Specimens in the shape of dumbbells were cut out using a die. Measurements were made with a crosshead speed of $500 \mathrm{~mm} \mathrm{~min}^{-1}$. The tensile strengths were reported in a unit of kilopascal $(\mathrm{kPa})$. The ultimate elongations were calculated by subtracting the original distances between the benchmarks from their total distances at the time of rupture.

\subsubsection{Ball Rebound Resilience}

The rebound resilience of foams was analyzed using a suitable device in correspondence with the Polish Norm PN-EN ISO 8307:2007. Depending on the elasticity of the samples, the ball rebounded to a certain height proportional to the rebound value by percentage.

\section{Results and Discussion}

\subsection{Analytical Methods}

The contents of functional groups in the obtained rapeseed oil-based derivatives were determined by analytical methods. The course of reactions was monitored by the investigation of the iodine value (LI), epoxy value (LEP) and hydroxyl value (LOH). The results are presented in Table 3.

As it can be seen, the true hydroxyl values are lower than those obtained in the theoretical calculations. The differences result from side reactions occurring during the epoxidation of rapeseed oil. 
Table 3. Properties of: rapeseed oil 1, epoxidized rapeseed oil (REPOX) 1, rapeseed oil-based polyol (RDEG) 1, rapeseed oil 2, REPOX 2 and RDEG 2.

\begin{tabular}{lllll}
\hline Sample & $\begin{array}{l}\text { LI } \\
\text { [g I } \mathbf{2} / \mathbf{1 0 0} \mathbf{g}]\end{array}$ & $\begin{array}{l}\text { LEP } \\
\text { [mol/100 g] }\end{array}$ & $\begin{array}{l}\text { LOH } \\
\text { [mol KOH/g] }\end{array}$ & $\begin{array}{l}\text { LOH theoretical } \\
\text { [mg KOH/g] }\end{array}$ \\
\hline Rapeseed oil 1 & 99 & - & - & - \\
REPOX 1 & 48.9 & 0.198 & 53 & - \\
RDEG 1 & 48.8 & 0 & 196 & 222 \\
Rapeseed oil 2 & 80.3 & - & - & - \\
REPOX 2 & 65.4 & 0.123 & 28 & - \\
RDEG 2 & 65.1 & 0 & 114 & 138 \\
\hline
\end{tabular}

\subsection{FTIR Analysis}

Fourier transform infrared (FT-IR) spectroscopy was used to follow the chemical structure of the polyols and identify their typical functional groups. The results of these analyses are presented in Figure 2.

Figure 2. Fourier transform infrared (FT-IR) spectra of RDEG 1 and RDEG 2.

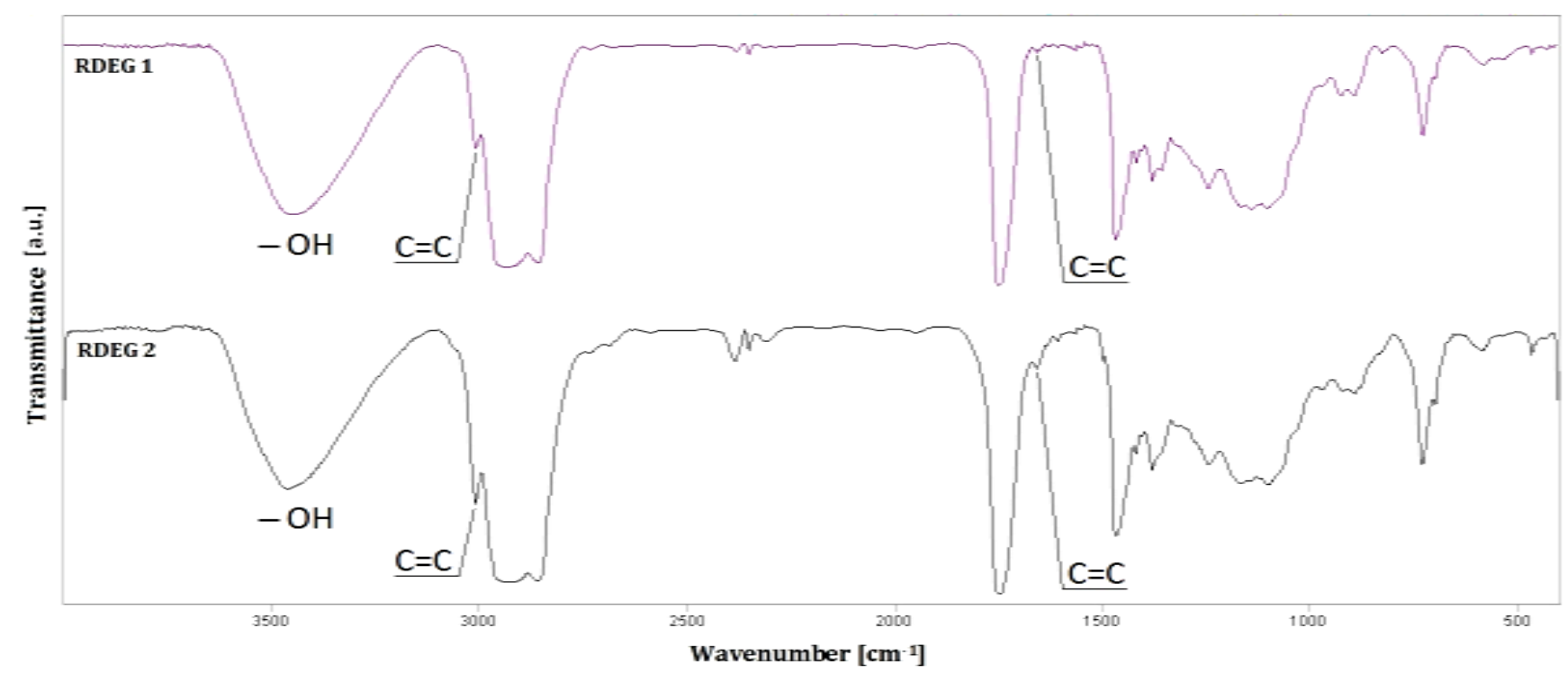

The characteristic absorption bands related to unsaturated bonds in the range of $1680-1640 \mathrm{~cm}^{-1}$ $(\mathrm{C}=\mathrm{C})$ and in the range of $3100-3000 \mathrm{~cm}^{-1}(=\mathrm{C}-\mathrm{H})$ are observed in the analyzed cases. The FT-IR spectra show distinctive absorbance peaks at $3464 \mathrm{~cm}^{-1}$ and $3473 \mathrm{~cm}^{-1}$ due to the presence of broad absorption bands related to the vibrations of hydroxyl groups. When comparing the FT-IR spectra of rapeseed oil-based polyols with different hydroxyl values, it is evident that diverse intensities of absorption bands can be seen for each polyol. This is compatible with the expected values and those obtained during analytical analysis.

\section{3. ${ }^{1}$ H NMR Analysis}

The ${ }^{1} \mathrm{H}$ nuclear magnetic resonance (NMR) spectra of rapeseed oil and its derivatives showed disappearance of unsaturated double bonds in the unsaturated fatty acids and confirmed the proceeding 
reactions of epoxidation and oxirane ring opening (Figure 3). Regions of chemical shifts include: (a) $\delta$ 0.88-0.93 ppm $-\left(\mathrm{CH}_{2}\right)_{\mathrm{n}}-\mathrm{CH}_{3}$; (b) $\delta 1.28-1.32 \mathrm{ppm}\left(\mathrm{CH}_{2}\right)_{\mathrm{n}}$; (c) $\delta 1.62 \mathrm{ppm}-\mathrm{CH}=\mathrm{CH}-\mathrm{CH}_{2}-\mathrm{CH}_{3}$; (d) $\delta$ 2.01-2.10 ppm $-\mathrm{CH}_{2}-\mathrm{CH}_{2}-\mathrm{CH}=\mathrm{CH}-$; (e) $\delta$ 2.31-2.38 ppm $-\mathrm{CH}_{2}-\mathrm{COO}-\mathrm{CH}_{2}-$; (f) $\delta 2.92-2.94$ ppm epoxy protons; (g) $\delta 3.64-3.81$ ppm hydroxyl protons; (h) $\delta 4.16-4.33 \mathrm{ppm}-\mathrm{CH}_{2}-\mathrm{CH}-\mathrm{CH}_{2}-$; (i) $\delta 5.27-5.41 \mathrm{ppm}-\mathrm{CH}=\mathrm{CH}-$.

Figure 3. ${ }^{1} \mathrm{H}$ nuclear magnetic resonance (NMR) spectra of rapeseed oil 1, REPOX 1 and RDEG 1.
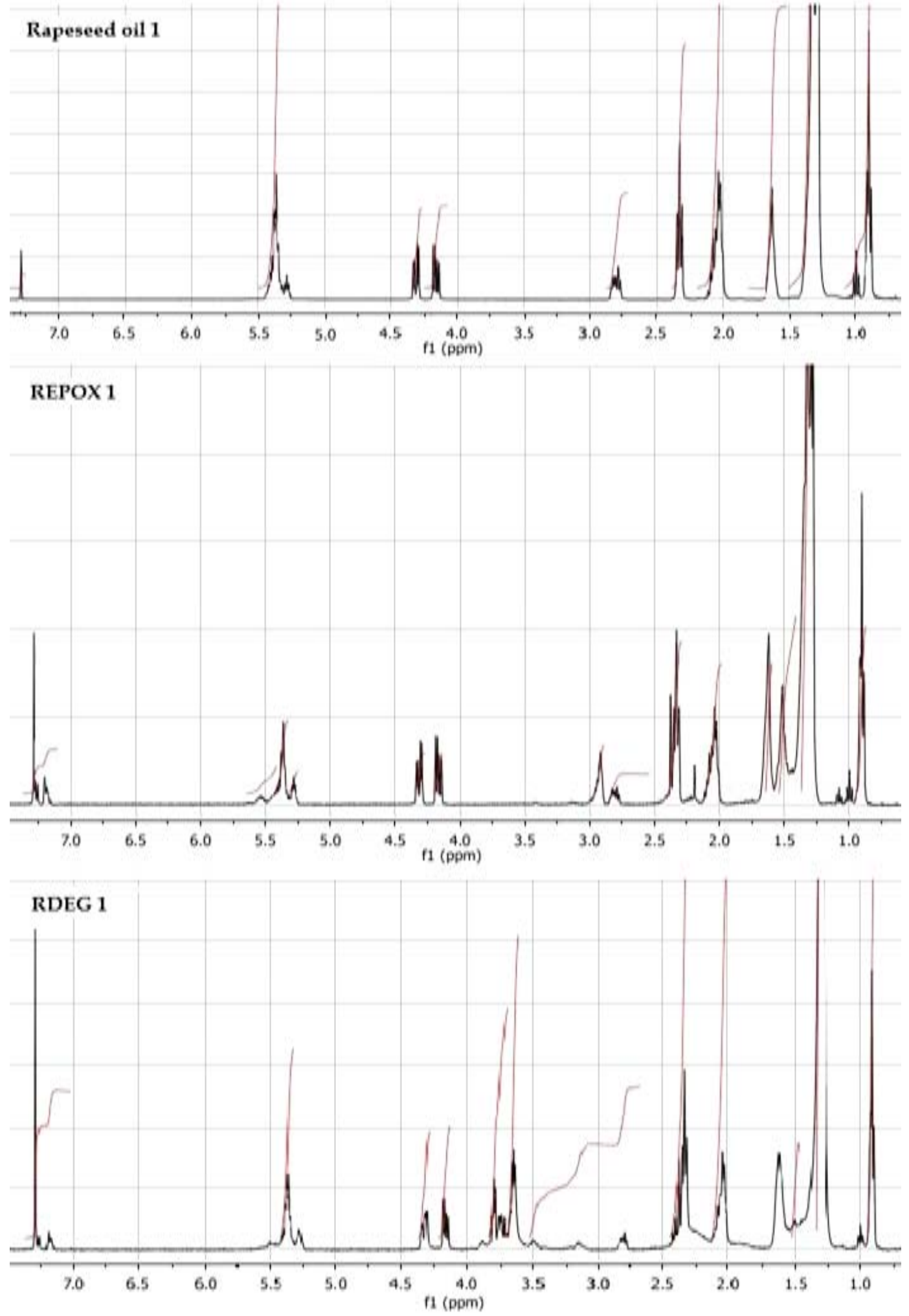


\subsection{SEC Analysis}

The molecular weights of the polyol samples used in this study were measured by SEC. The chromatograms are shown in Figure 4.

Figure 4. Distribution of molecular weights of RDEG 1 and RDEG 2.

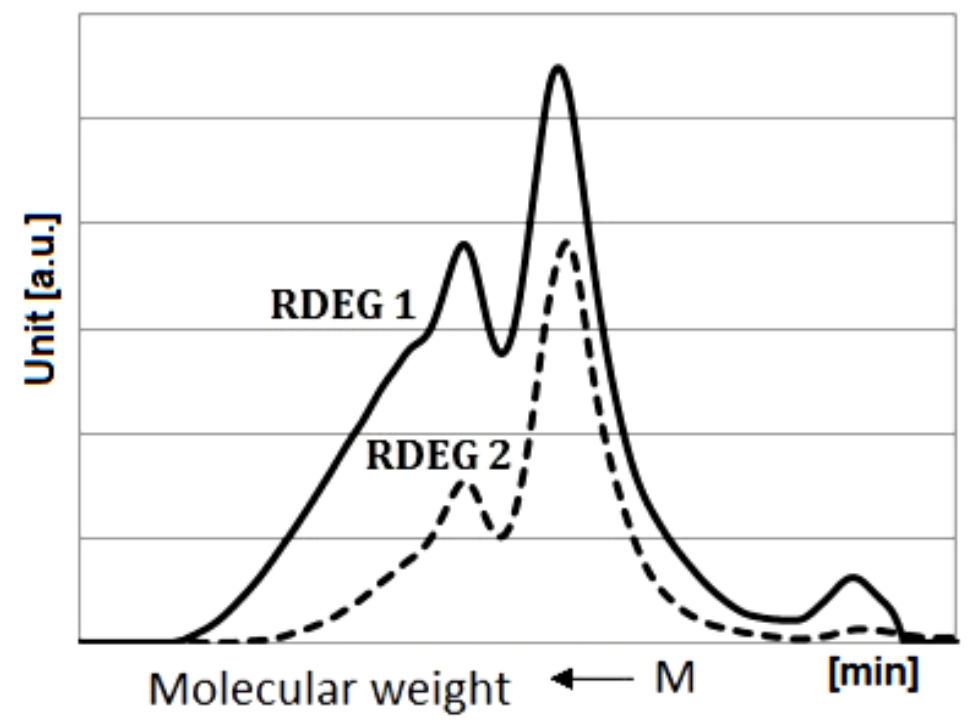

The calculated molecular weights of polyols were $1488 \mathrm{~g} / \mathrm{mol}$ and $1235 \mathrm{~g} / \mathrm{mol}$ for RDEG 1 and RDEG 2, respectively. The functionalities of polyols were estimated on the basis of the hydroxyl values and molecular weights. The resulting functionality values were equal to 5.2 and 2.5 for RDEG 1 and RDEG 2, respectively.

Second broad peaks were found in SEC traces of the obtained polyols. This was probably due to both variations in fatty acid substituents and side reactions during the formation of polyols, mainly polymerization, namely formation of dimers and trimers through the oxirane ring opening by hydroxyl groups. It depended on diverse factors e.g., temperature, time, catalyst concentration, and DEG-epoxy molar ratio.

\subsection{Rheological Properties}

The type of polyol affects the physical properties of the prepared foams. The viscosity of polyols has an appreciable effect on the foaming time, liquidity of the reaction mixture and appropriate filling of the mold. The dynamic viscosities of rapeseed oil-based polyols were determined using a rheometer. Figure 5 present results of measurements determining the effect of temperature and shearing rate on dynamic viscosity of polyols.

It was found that the viscosity decreases with higher shear rate and temperature. Accordingly, the studied polyols are non-Newtonian fluids. The viscosity values of polyols, measured at a temperature of $25{ }^{\circ} \mathrm{C}$ and at a shear rate equal $1000 \mathrm{~s}^{-1}$, were $705.7 \mathrm{mPa} \mathrm{s}, 1281 \mathrm{mPa} \mathrm{s}$ and $297.7 \mathrm{mPa} \mathrm{s}$ for Arcol 1108, RDEG 1 and RDEG 2, respectively. 
Figure 5. Effect of coagulation speed or temperature on dynamic viscosity of polyols.
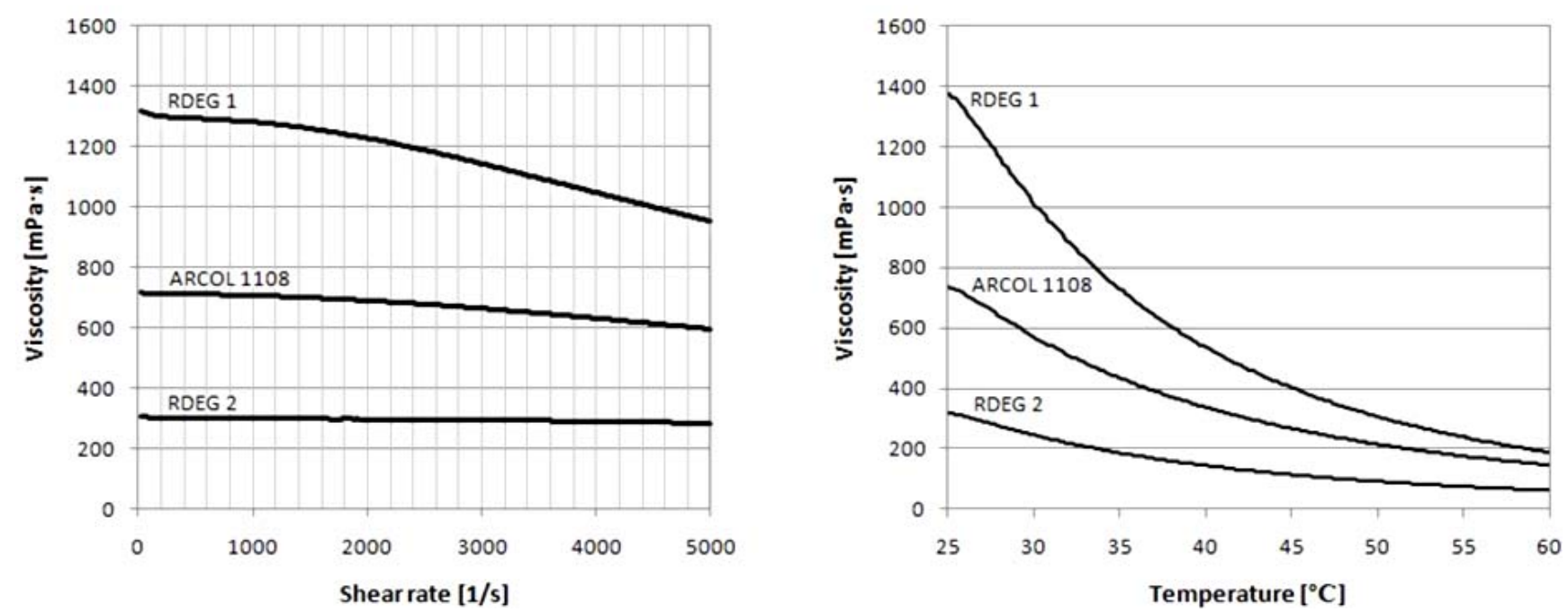

\subsection{Morphology and Properties of Polyurethane Foams}

Selected formulations used to make TDI based foams were chosen to illustrate the effect of bio-polyol content on foam properties.

\subsubsection{Cell Structure Analysis}

The first important point to be studied was the determination of the number of cells per square millimeter and their average area (Table 4). As it can be seen, the small average area of cells and their higher number per $\mathrm{mm}^{2}$ caused an increase of apparent density of the obtained porous bio-based materials.

Table 4. Structural properties of polyurethane foams.

\begin{tabular}{cccc}
\hline Sample & Average number of cells & Average area of cells $\left[\mathbf{m m}^{2}\right]$ & Apparent density $\left[\mathbf{k g} / \mathbf{m}^{3} \mathbf{]}\right.$ \\
\hline RF-85 & 9 & 0.0561 & 21.7 \\
R1DG3-85 & 13 & 0.0386 & 20.0 \\
R2DG3-85 & 15 & 0.0356 & 20.9 \\
R1DG3-65 & 24 & 0.0205 & 21.8 \\
R1DG5-65 & 22 & 0.0239 & 22.2 \\
R1DG7-65 & 19 & 0.0274 & 24.7 \\
\hline
\end{tabular}

A series of pictures showing the cell structure of flexible foams was obtained by using the optical microscope (Figure 6).

The cells of the foams showed similar spherical appearance in microstructure. The addition of natural oil-based polyols supported the effect of surfactants. As can be seen from Figure 5 and Table 4, the modification of a reference system with hydroxyl derivatives of rapeseed oils provided more homogeneous cell structure and decreased the average cell area of the foams. 
Figure 6. Optical micrographs of cross-sectioned polyurethane foams $(\times 2.5)$.

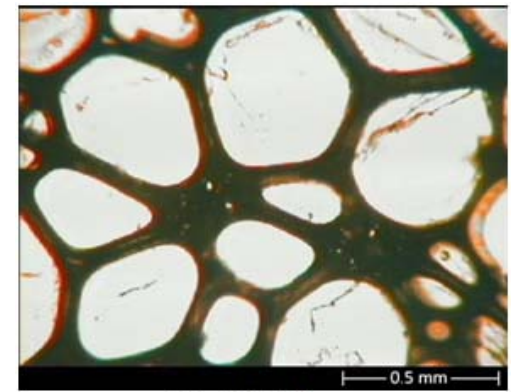

(a) $R F-85$

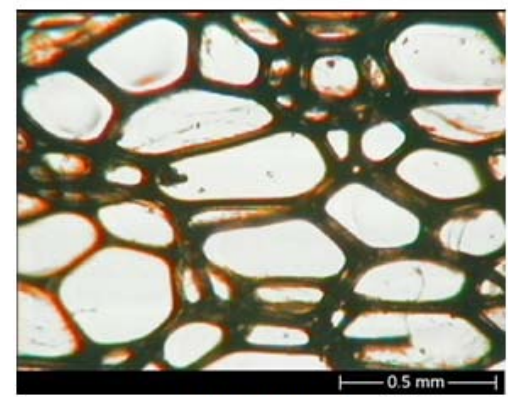

(d) RIDG3-65

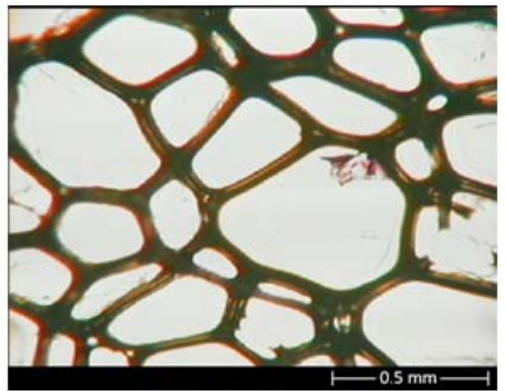

(b) RIDG3-85

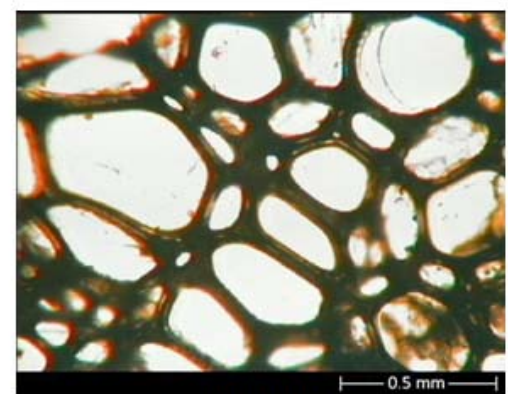

(e) RIDG5-65

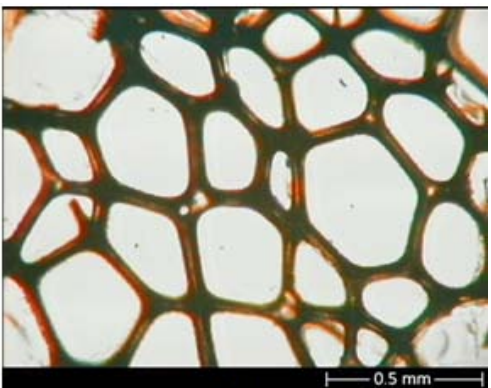

(c) $R 2 D G 3-85$

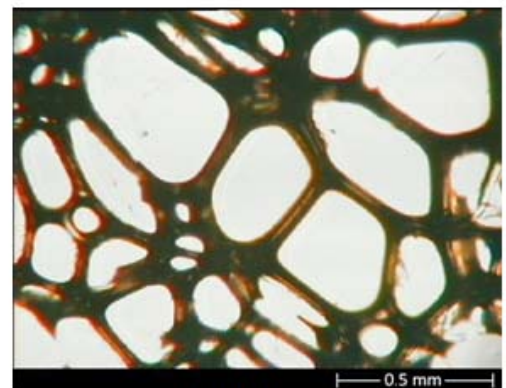

(f) $R I D G 7-65$

\subsubsection{Compression Force Deflection Test (Compressive Strength)}

The resulting foams had similar apparent densities of about $20-25 \mathrm{~kg} / \mathrm{m}^{3}$. The plots of compressive strength and apparent density versus foam formulations are shown in Figure 7.

Figure 7. Apparent density and compressive strength of polyurethane (PUR) foams measured in perpendicular and parallel rise directions.
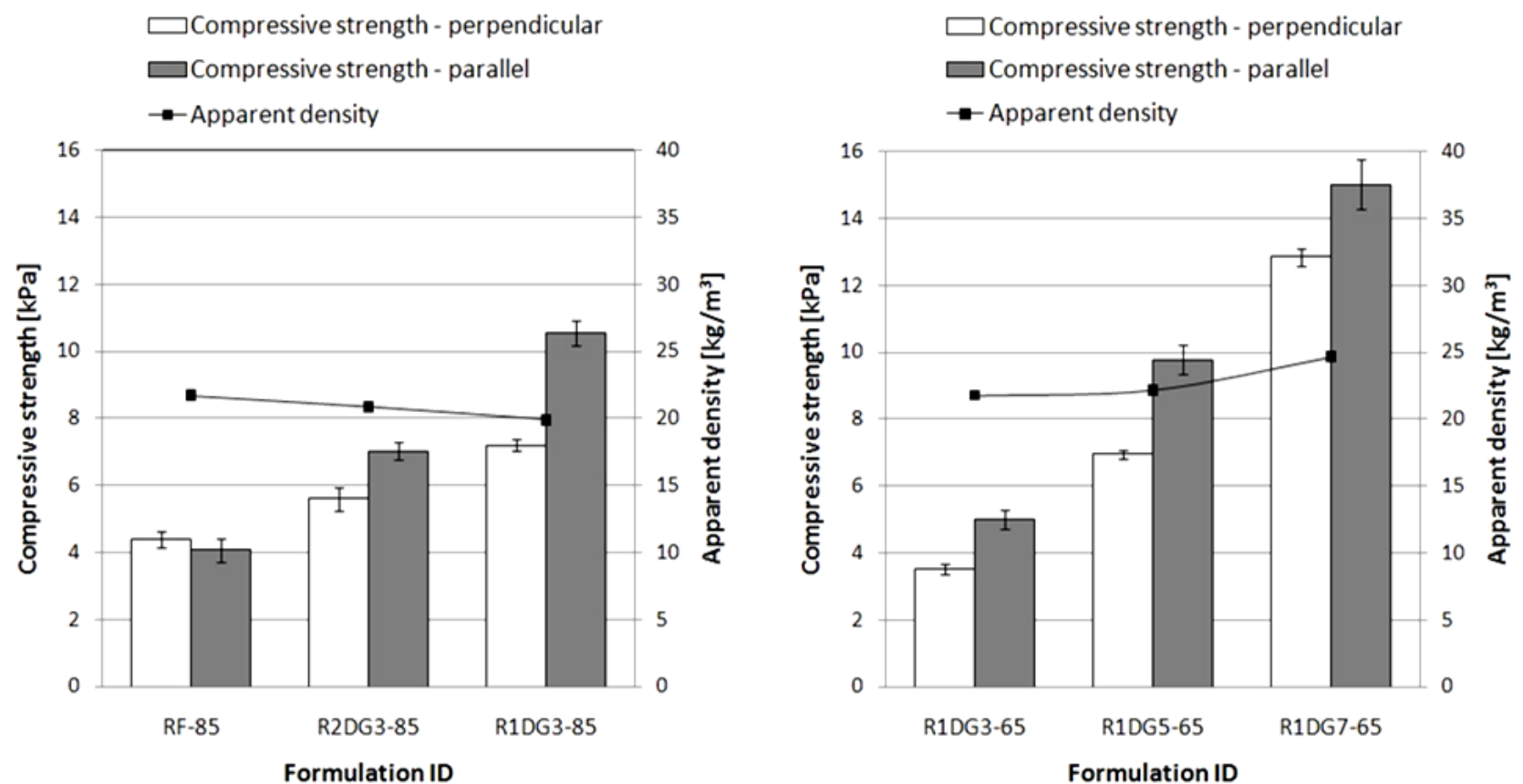

The noteworthy point arising from the graphs is the difference in the compression strength values measured in different directions of foam growth. The results indicate that the lower values are obtained 
in perpendicular direction. This is to be expected since the foam cells are elongated according to the direction of free foaming of the reaction mixture. However, in the case of RF-85, the opposite relationship can be noticed. This difference is connected with a shorter foaming time observed for the reference foam. Furthermore, with an increase of vegetable polyol content in foam formulations, the compression strength values increased. This can be explained by different cross-linking densities of the obtained foams.

\subsubsection{Tensile Properties}

The impact of foam formulations on their tensile properties giving some indication of foams durability is presented in Figure 8.

Figure 8. Elongation at break and tensile strength of PUR foams.
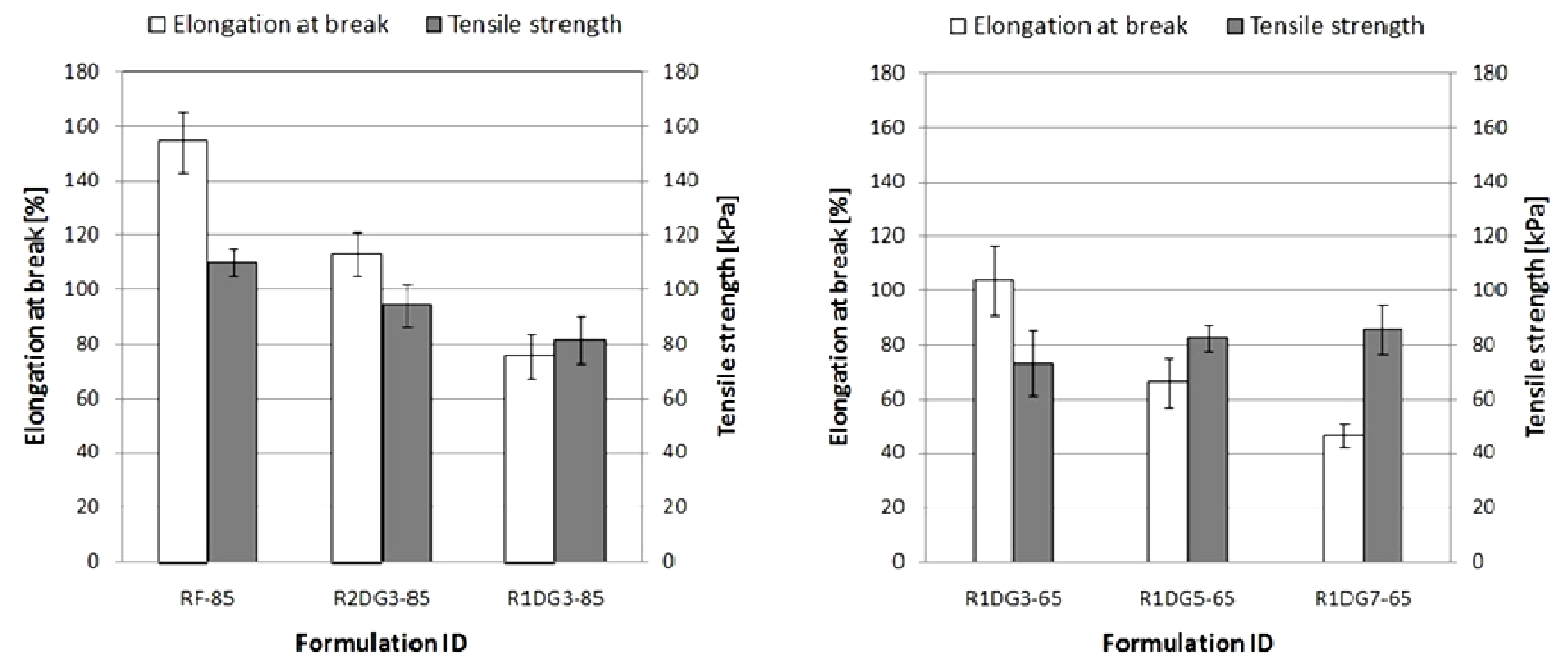

Compared with reference foams, elongation at break and tensile strength of rapeseed oil-based foams were lower. In turn, much higher tensile strength and elongation values were obtained for foams modified with polyol of lower hydroxyl value. In general, with an increase in bio-polyol contents in PUR formulations, the elongation at break values decreased. In the case of tensile strength values an inverse relationship can be seen. The increase in cross-linking density produces stiffer foams with reduced elongations at break and higher tensile strength values.

\subsubsection{Ball Rebound Resilience}

The ball rebound resilience data for the analyzed foams are shown in Figure 9. Typically, values less than $25 \%$ define viscoelastic foams.

In contrast to the parallel growth direction, higher values were obtained in perpendicular direction to the foam rise. When comparing the resilience values for flexible foams, it is evident that the rebound heights result from cell anisotropy and elongation in the foam's growth direction. Moreover, it is interesting to note that the modification of reference PUR foams influenced the decrease of resilience 
values. This relationship is related to different hydroxyl values of polyols and cross-linking densities of the obtained PUR foams.

Figure 9. Resilience of PUR foams measured in perpendicular and parallel rise directions.
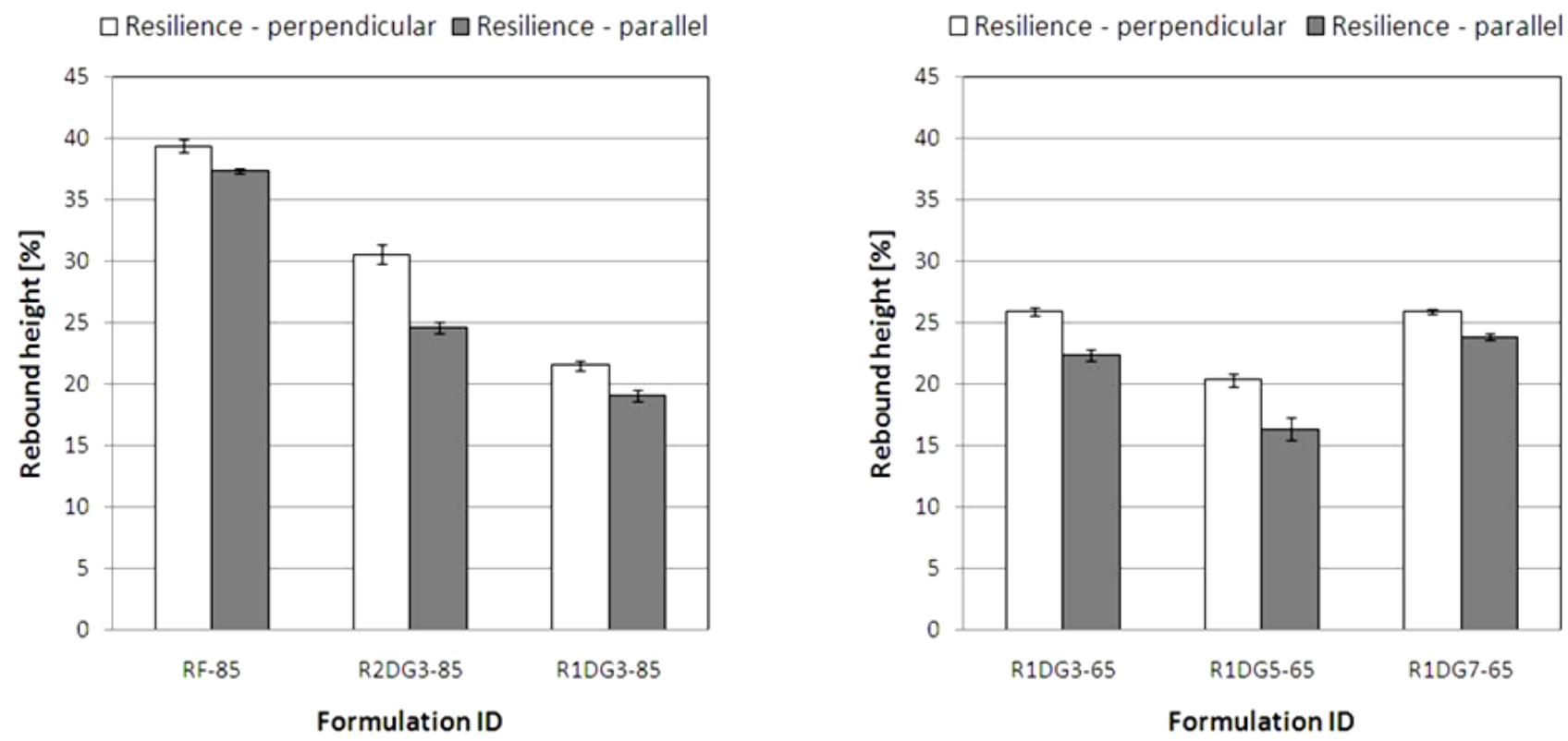

\section{Conclusions}

Nowadays, vegetable oil-based polyols constitute a significant green opportunity. It is important to replace petroleum polyols with analogues based on vegetable oils, e.g., rapeseed oil, which is a low-cost and readily available renewable feedstock. The usage of green polyols reduces dependence on foreign petroleum, decreases the negative effects on human health and the environment, as well as increases the usage of renewable feedstock and agricultural products. Therefore, the obtained natural oil-based polyols are competitive with the polyols synthesized from petrochemical raw materials. On the other hand, the impact of biopolyols on food production should be taken into account. However, there is a significant difference in scale between biofuels and biopolyols. The fuel market is considerably larger than the industrial market. Nevertheless, future technologies should apply more non-food sources in the production of raw materials.

Two rapeseed oil-based polyols with hydroxyl values 196 and $114 \mathrm{mg} \mathrm{KOH/g}$ were obtained in a large amount and about $600 \mathrm{~g}$ were used for synthesis of flexible PUR foams. Foam formulations were selected to illustrate the effects of the renewable content (polyols from vegetable oils) on the foam properties. The conducted analysis revealed a significant influence of the examined factors upon the foam characteristics. Moreover, experimental results showed that applying partially substituted petroleum polyols with natural oil-based polyols in flexible foam formulations lead to the improvement of cell structure and compression stress values of the foams. However, it could be observed that foams obtained by replacement of $30 \mathrm{wt} \%$ of petroleum polyols exhibited better properties than those with 50 and $70 \mathrm{wt} \%$ replacement. It related to cellular structure, tensile strength values as well as resilience values. The basic area worthy of exploring is the optimization of additives, catalysts and surfactants for natural oil-based flexible foams. 


\section{Acknowledgments}

This work was undertaken as part of the EU sponsored COST Action CM0903 "Utilisation of Biomass for Sustainable Fuels \& Chemicals (UBIOCHEM)". The paper was presented during "Materials and Technologies for Green Chemistry" Conference, SustainChem2011, Tallin, July 2011.

\section{References}

1. Genova, R.; Malsam, J.; Zlatanic, A.; Wazirzada, Y. Bio-based polyols of the flexible slabstock foam industry. J. Oil Palm Res. 2008, 20, 53-60.

2. Veenendaal, B. Renewable content in the manufacture of polyurethane polyols-An opportunity for natural oils. PU Mag. Int. 2007, 4, 352-359.

3. Prociak, A. Heat Insulating Polyurethane Materials of New Generation; Cracow University of Technology Press: Cracow, Poland, 2008; pp. 16-19.

4. Zhang, L.; Jeon, H.K.; Malsam, J.; Herrington, R.; Macosko, C.W. Substituting soybean oil-based polyol into polyurethane flexible foams. Polymer 2007, 48, 6656-6667.

5. Casati, F.M.; Dawe, B.; Fregni, S.; Miyazaki, Y. Natural oil polyols: Applications in moulded polyurethane foams. PU Mag. Int. 2008, 5, 246-253.

6. Wirpsza, Z. Polyurethanes: Chemistry, Technology, and Applications; Ellis Horwood Ltd.: New York, NY, USA, 1994; pp. 517.

7. Randall, D.; Lee, S. The Polyurethanes Book; Wiley Ltd.: New York, NY, USA, 2002; pp. 169-188.

8. Dounis, D.V.; Wilkes, G.L. Structure-property relationships of flexible polyurethane foams. Polymer 1997, 38, 2819-2828.

9. Zhang, L. Structure-Property Relationship of Polyurethane Flexible Foam Made From Natural Oil Polyols. Ph.D. Thesis, University of Minnesota, Twin Cities, MN, USA, September 2008.

10. Zlatanic, A.; Lava, C.; Zhang, W.; Petrovic, Z.S. Effect of structure on properties of polyols and polyurethanes based on different vegetable oils. J. Polym. Sci. 2004, 42, 809-819.

11. Gunstone, F.D. Vegetable Oils in Food Technology: Composition, Properties and Uses; Blackwell Publishing: Oxford, UK, 2002; pp. 99-110.

12. Milchert, E.; Smagowicz, A. The influence of reaction parameters on the epoxidation of rapeseed oil with peracetic acid. J. Am. Oil Chem. Soc. 2009, 86, 1227-1233.

13. John, J.; Bhattacharya, M.; Turner, R.B. Characterization of polyurethane foams from soybean oil. J. Appl. Polym. Sci. 2002, 86, 3097-3107.

14. Herrington, R.; Malsam, J. Flexible Polyurethane Foams Prepared Using Modified Vegetable Oil-Based Polyols. U.S. Pat. Appl. 10,877,834, 25 June 2004.

15. Prociak, A. Heat-insulating properties of rigid polyurethane foams synthesized with use of vegetable oil-based polyols. Polimery 2008, 53, 195-200.

16. Pielichowski, J.; Prociak, A.; Czub, P. Sposób Otrzymywania Składnika Poliolowego Przeznaczonego Do Syntezy Sztywnych Pianek Poliuretanowych. Patent PL 205405 B1, Poland, 2010. 
17. Pielichowski, J.; Prociak, A.; Czub, P. Sposób Otrzymywania Składnika Poliolowego Przeznaczonego Do Syntezy Elastycznych, Poliuretanowych Materiałów Porowatych. Patent PL 206376 B1, Poland, 2010.

18. Prociak, A. Blowing agents and foaming processes: properties of polyurethane foams modified with natural oil-based polyols. Cell. Polym. 2007, 26, 381-392.

19. Prociak, A. Rigid polyurethane foams modified with vegetable oil-based polyols. In Proceedings of UTECH Europe 2006, Maastricht, The Netherlands, 28-30 March 2006 [CD-ROM]; pp. 1-10.

20. Bogdal, D.; Prociak, A. Microwave-Enhanced Polymer Chemistry and Technology; Blackwell Publishing Professional: Ames, IA, USA, 2007; pp. 3-31.

21. Dworakowska, S.; Bogdal, D.; Prociak, A. Synthesis of polyols from rapeseed oil. In Proceedings of the 14th International Electronic Conference on Synthetic Organic Chemistry, Basel, Switzerland, 1-30 November 2010; pp. 1-5.

(C) 2012 by the authors; licensee MDPI, Basel, Switzerland. This article is an open access article distributed under the terms and conditions of the Creative Commons Attribution license (http://creativecommons.org/licenses/by/3.0/). 